\title{
МИНЕРАЛОГИЧЕСКАЯ ХАРАКТЕРИСТИКА ЮЛГАЗЕСКИХ ОТЛОЖЕНИЙ ОКРЕСТНОСТИ МААРДУ
}

В настоящее время в связи с уточнением расположения границы между кембрием и ордовиком на Восточно-Европейской платформе актуальным становится всестороннее изучение юлгазеских отложений, залегающих на стыке этих двух систем в Северной Эстонии.

Литологическое описание, распространение, мощность, характеристика границ имеются в многочисленных работах (Мююрисепп, 1958, 1960; Лоог, Кивимяги, 1968; Рыымусокс и др., 1975 и др.). Минералогия юлгазеских отложений, в частности их стратотипического разреза, изучена недостаточно. Имеется лишь одна сводка о минеральном составе этих отложений на основе семи проб из разных разрезов (Хейнсалу, Вийдинг, 1978). Исходя из этого ниже излагаем результаты изучения минерального состава юлгазеских отложений по двум разрезам стратотипической местности данного стратона - в окрестности Маарду.

Настоящее сообщение основывается на изучении 21 пробы юлгазеских отложений, отобранных из обнажения у штольни бывшего рудника Юлгазе и разреза скв. 1046 (рис. 1). Образцы из этого разреза предоставил К. Хазанович, за что автор выражает ему признательность.

Учитывая непосредственную зависимость минерального состава от гранулометрии пород (Батурин, 1947; Окнова, 1972 и др.), ниже приводим вкратце и гранулометрическую характеристику юлгазеских отложений рассматриваемой территории. Название пород согласно их гранулометрии по номенклатуре, принятой в Институте геологии АН ЭССР (Раукас, 1981), дано в табл. 1. Там же, рядом с названием пород приведено в процентах суммарное содержание зерен, диаметром более 0,05 мм. Этот показатель, отражающий гидродинамическую активность обстановки седиментации, в юлгазеских отложениях окрестности Маарду довольно высокий (обычно более 50, а местами даже более $90 \%$, табл. 1).

Поскольку гравийные зерна были отмечены только в двух случаях (в сотых долях процентов), данные гранулометрического анализа представлены на треугольной диаграмме в системе песок-алевритпелит (рис. 2). Дополнительно следует отметить, что основными являются мелкопесчаная $(0,1-0,25$ мм), крупноалевритовая $(0,05-0,1$ мм) и пелитовая $(<0,01$ мм) фракции, составляющие всегда более $90 \%$. Дефицитность зерен крупнее мелкого песка скорее всего связана с тем, что основным источником кластогенного материала в юлгазеское время послужили обнажившиеся на окружающей суше осадочные образования, в том числе нижнего и среднего отделов кембрия, содержащие в незначительном количестве грубообломочный материал. Выдержанные тиховодные условия осадконакопления в рассматриваемом районе отмечены только в первой половине юлгазеского времени. Об этом свидетельствуют прослои глинистых пород в низах обоих изученных разрезов (рис. 1). Повышенная глинистость в верхней части разреза 
Некоторые литолого-минералогические показатели юлгазеских отложений окрестности Маарду

\begin{tabular}{|c|c|c|c|c|c|}
\hline \multirow{3}{*}{$\begin{array}{l}\text { Номер } \\
\text { пробы }\end{array}$} & \multirow{3}{*}{$\begin{array}{c}\text { Глубина } \\
\text { опробования }\end{array}$} & \multirow{3}{*}{$\begin{array}{c}\text { Название породы } \\
\text { по ее гранулометрии }\end{array}$} & \multirow{3}{*}{ 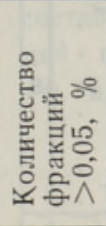 } & \multicolumn{2}{|c|}{ Соотношения } \\
\hline & & & & Кварц & $\begin{array}{l}\text { Лейко- } \\
\text { ксен }\end{array}$ \\
\hline & & & & $\begin{array}{c}\text { Полевой } \\
\text { шпат }\end{array}$ & $\begin{array}{l}\text { Ильме- } \\
\text { нит }\end{array}$ \\
\hline Ю-2 & $0,00-0,75^{*}$ & песчанистый алевролит & 94 & 10,1 & 12,9 \\
\hline Ю-3 & $0,75-0,85^{*}$ & глина & 1 & 17,2 & 1,4 \\
\hline Ю- 4 & $0,85-1,10^{*}$ & алевролит & 92 & 19,8 & 6,9 \\
\hline Ю-5 & $1,10-1,15^{*}$ & глина & 1 & 15,3 & 2,5 \\
\hline Ю- 6 & $1,20-3,20^{*}$ & песчаный алевролит & 97 & 13,7 & 0,6 \\
\hline Ю-7 & $3,20-4,40^{*}$ & алевролит & 95 & 10,4 & 7,7 \\
\hline Ю- 8 & $4,50-6,50^{*}$ & алевритовый песчаник & 97 & 24,0 & 0,3 \\
\hline $1046 / 14$ & $24,80-24,90$ & глина & 1 & 7,2 & 1,5 \\
\hline $1046 / 13$ & $24,50-24,60$ & глина & 7 & 11,8 & 0,8 \\
\hline $1046 / 12$ & 21,00 & пелитисто-песчаный алевролит & 86 & 13,3 & 0,6 \\
\hline $1046 / 11$. & 20,50 & $\begin{array}{l}\text { алевритисто-пелитистый миксто- } \\
\text { лит }\end{array}$ & 66 & 57,8 & 0,4 \\
\hline $1046 / 10$ & 20,25 & $\begin{array}{l}\text { песчанисто-пелитовый алевро- } \\
\text { лит }\end{array}$ & 57 & 42,2 & 0,5 \\
\hline $1046 / 9$ & 19,30 & $\begin{array}{l}\text { пелитисто-алевритовый песча- } \\
\text { ник }\end{array}$ & 89 & 32,0 & 0,3 \\
\hline $1046 / 8$ & 19,20 & $\begin{array}{l}\text { песчанисто-алевритистый микс- } \\
\text { толит }\end{array}$ & 81 & 23,9 & 0,3 \\
\hline $1046 / 7$ & 19,00 & $\begin{array}{l}\text { алевритисто-пелитистый микс- } \\
\text { толит }\end{array}$ & 66 & 20,2 & 0,3 \\
\hline $1046 / 6$ & 18,40 & $\begin{array}{l}\text { пелитисто-алевритовый песча- } \\
\text { ник }\end{array}$ & 78 & 32,3 & 0,4 \\
\hline $1046 / 5$ & 18,20 & песчаный алевролит & 97 & 19,0 & 0,6 \\
\hline $1046 / 4$ & 18,10 & $\begin{array}{l}\text { песчанисто-алевритистый микс- } \\
\text { толит }\end{array}$ & 86 & 21,7 & 0,2 \\
\hline $1046 / 3$ & 17,70 & песчанисто-алевритистая глина & 27 & 17,8 & 0,1 \\
\hline $1046 / 2$ & $17,20^{\circ}$ & пелитисто-песчаный алевролит & 84 & 26,0 & 0,6 \\
\hline $1046 / 1$ & 16,80 & песчанисто-алевритистая глина & 17 & 21,6 & 0,1 \\
\hline
\end{tabular}

* Интервалы показаны от нижней границы юлгазеских слоев.

скв. 1046 либо указывает на неодинаковый денудационный срез стратона, либо имеет локальную природу, что говорит о защищенности участка от сильного волнения. Отмеченные черты гранулометрии юлгазеских отложений накладывают отпечаток и на их минеральный состав.

Минеральный состав пород изучался иммерсионным методом в крупноалевритовой фракции $(0,1-0,05$ мм), предварительно разделенной в бромоформе (уд. в. 2,89 $\mathrm{r} / \mathrm{cm}^{3}$ ) на легкую и тяжелую фракции. Результаты минералогического анализа приведены в табл. 2. Процентные содержания минералов или их групп в тяжелой фракции высчитаны по трехступенчатой схеме подсчета (Вийдинг, 1976) и только для минерального компонента пород. При пересчете исключен биогенный компонент, представленный главным образом обломками фосфатсодержаших створок беззамковых брахиопод. Этот компонент составляет до $20 \%$ легкой фракции и до $95 \%$ тяжелой.

Любопытно хорошее совпадение данных минералогических анализов гранулометрически однотипных пород обоих разрезов, несмотря на то, что один представлен обнажением, а второй - керном скважины и что в одном случае опробование проводили бороздовым, а во втором - точечным методом. На основании сказанного и с учетом того 


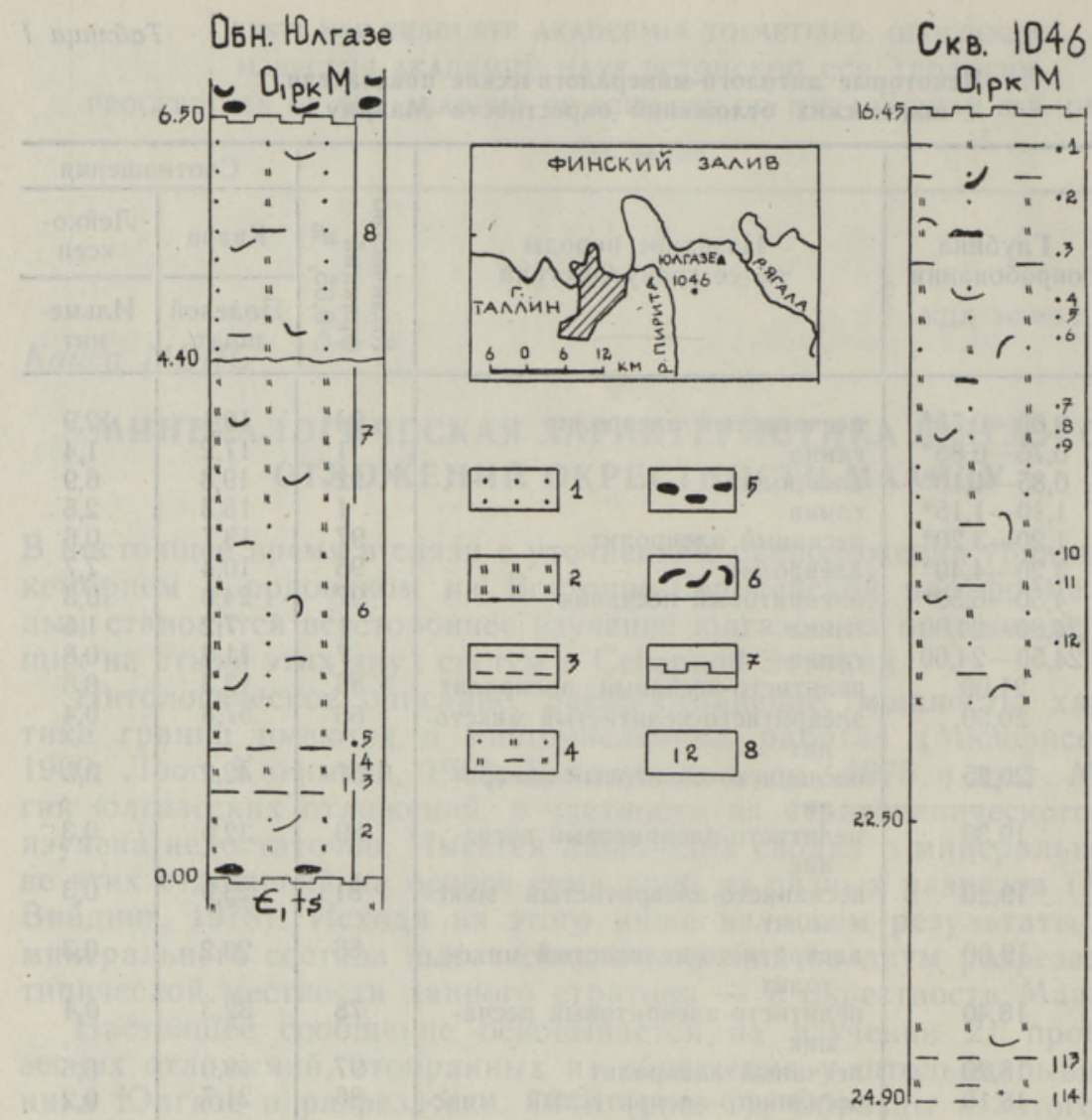

Рис. 1. Расположение изученных разрезов, место отбора проб и их номера. $I$ - песчаник, 2 - алевролит, 3 - глина, 4 - смешанная порода, 5 - гальки фосфатизированных пород, 6 - створки беззамковых брахиопод и их детрит; 7 - поверхность перерыва, 8 - место отбора пробы и номер.

обстоятельства, что данные минерального состава разрезов обнажения Юлгазе и скважины 1046 хорошо согласуются с ранее приведенными для юлгазеских отложений (Хейнсалу, Вийдинг, 1978), был подсчитан средний минеральный состав песчано-алевритовых и глинистых пород рассматриваемых слоев окрестности Маарду (рис. 3).

Особенность минерального состава кластогенного компонента юлгазеских отложений - высокая степень зрелости, выраженная в преобладании мономинеральных кварцевых разновидностей песчано-алевритовых пород с характерной цирконо-турмалино-рутиловой ассоциацией тяжелых прозрачных аллотигенных минералов (табл. 1, 2). Легкая фракция почти полностью сложена кварцом; содержание полевых шпатов редко превышает $10 \%$, и это наблюдается только в глинистых породах. У зерен полевых шпатов часто обнаруживаются прозрачные неокатанные идиоморфные регенерационные каемки, явно свидетельствующие об их аутигенной природе. Мало также листочков слюд, среди них преобладает мусковит. Аутигенных минералов в легкой фракции обычно меньше $1 \%$ и они представлены главным образом глауконитом и карбонатами.

Тяжелая фракция в минеральном компоненте крупного алеврита составляет десятые, а местами и сотые доли процента. Тяжелая фракция характеризуется прежде всего явным преобладанием аллотигенных минералов над аутигенными, за исключением проб из глинистых 


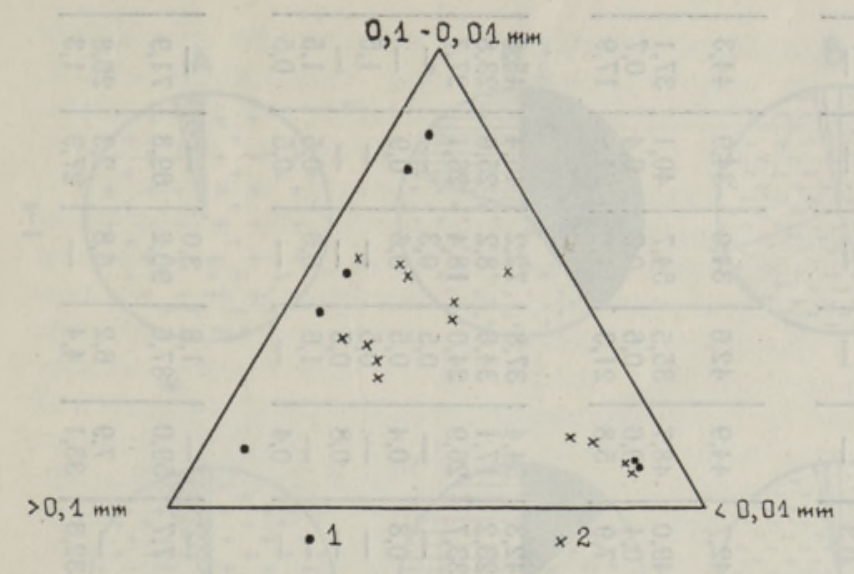

Рис. 2. Гранулометрический состав юлгазеских отложений в обнажении Юлгазе (I) и в разрезе скв. 1046 (2).

прослоев (табл. 2; рис. 3). Как в песчано-алевритовых, так и в глинистых разностях юлгазеских отложений среди тяжелых аллотигенных в близких количествах представлены как рудные, так и прозрачные минералы. В группу аллотигенных рудных минералов включены, кроме ильменита, неизмененные или малоизмененные зерна лейкоксена. Последний минерал относится к этой группе условно, из-за ее двоякой природы. Судя по форме и размерам зерен лейкоксена, часть их поступила в бассейн уже в таком виде, т. е. имеет аллотигенное происхождение. Часть его зерен образовалась путем лейкоксенизации ильменита в ходе постседиментационных процессов. На это указывает множество зерен ильменита,! покрытых пятнами лейкоксена. Зерна лейкоксена, замещенные больше чем на половину анатазом, включены в группу аутигенных минералов. Соотношение ильменита и лейкоксена представлено в табл. 1.

Ассоциации тяжелых аллотигенных прозрачных минералов в песчано-алевритовых и глинистых пюродах на удивление близки между собой (рис. $3, B$ ). Более $90 \%$ этой группы сложено господствующей триадой - циркон-турмалин-рутил. Циркон представлен преимущественно окатанными изометрическими бесцветными разновидностями. Наряду с этими, но в меньшинстве, наблюдаются розовые, зональные и игольчатые разновидности. Малаконизация циркона не характерна для юлгазеских пород. Чаще всего этот процесс развивается в тех же интервалах, где наблюдается усиленное анатазообразование по лейкоксену. Среди турмалинов много плеохроирующих в зеленых или от зеленого до коричневого тонах, за ними следуют коричневые разновидности. В виде единичных зерен, но в каждой пробе, обнаружены синие и бесцветные турмалины. Среди рутилов много красноватокоричневых и темно-коричневых и гораздо меньше золотисто-желтых зерен. Характерно, что зерна рутила обычно хуже окатаны, чем зерна циркона и турмалина. Помимо доминирующей триады, среди устойчивых минералов этой группы эпизодически наблюдаются титанит и корунд. Среднеустойчивые, составляющие обычно менее $2 \%$ данной минеральной группы, представлены спорадически дистеном, апатитом и бесцветными угловатыми зернами граната, поверхность которых пятнами мелкоступенчатая. Малоустойчивые минералы, хотя и в незначительном количестве (редко до $4 \%$ ), являются постоянными представителями рассматриваемой группы минералов. Чаще всего они представлены амфиболами и реже эпидотом.

Для многих аллотигенных минералов как тяжелой, так и легкой фракции, особенно для рутила, циркона, ильменита и кварца, характерны фосфатные пятна и пленкй на их зернах, 


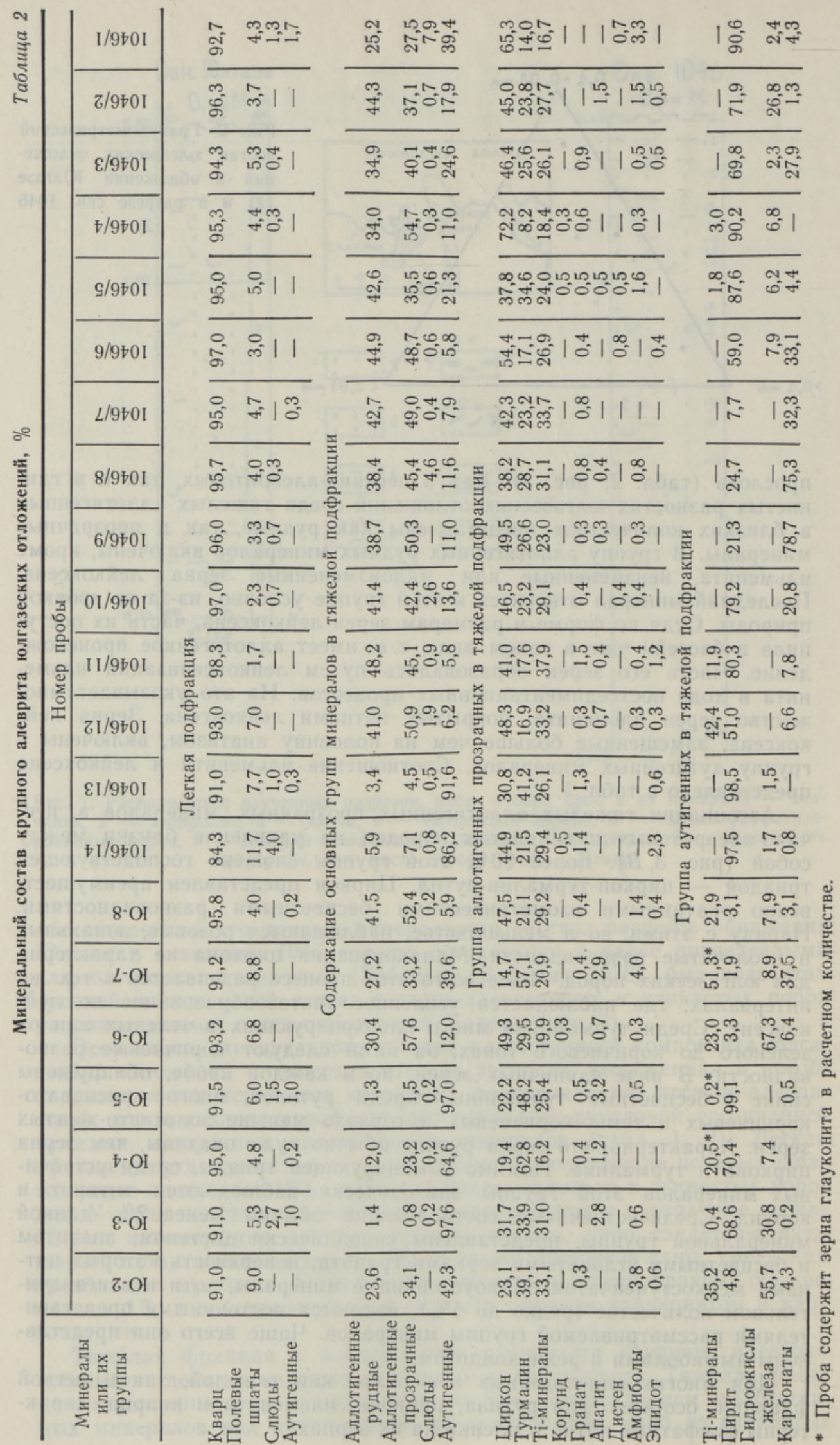




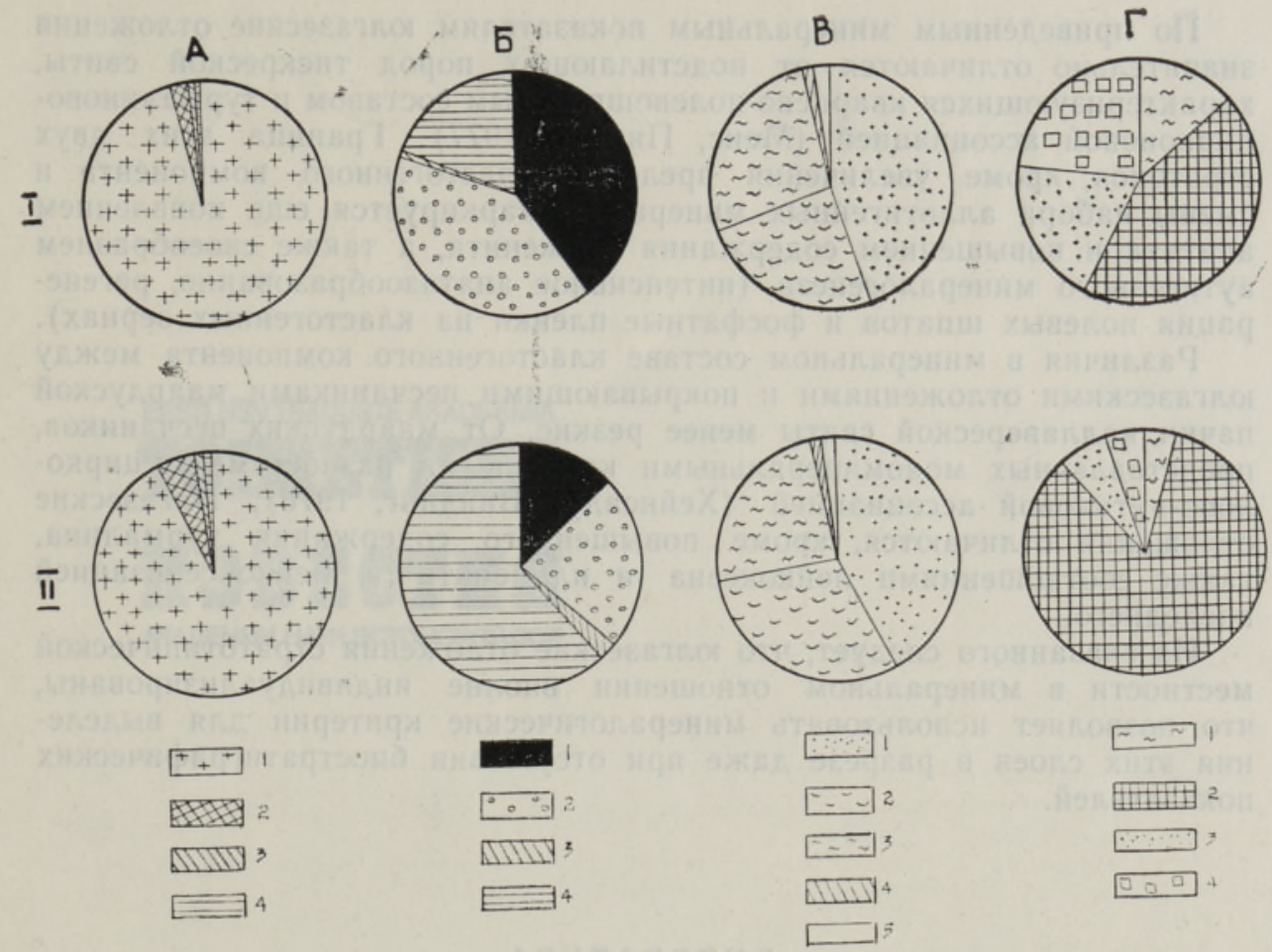

Рис. 3. Минеральный состав крупного алеврита песчано-алевритовых (I) и глинистых (II) пород юлгазеских отложений в окрестности Маарду. $A-$ легкая фракция: $1-$ кварц, 2 - полевые шпаты, 3 - слюды, 4 - аутигенные минералы; 5 - основные группы минералов тяжелой фракции: 1 - аллотигенные рудные, 2 - аллотигенные прозрачные, 3 - слюды, 4 - аутигенные минералы; $B$ - группа тяжелых аллотигенных прозрачных минералов: 1 - циркон, 2 - турмалин, 3 - Ті-минералы, 4 среднеустойчивые (гранат, апатит, дистен), 5 - малоустойчивые (амфиболы, эпидот, пироксены); $\Gamma$ - группа тяжелых аутигенных минералов: 1 - анатаз, $2-$ пирит, 3 - гидроокислы железа, 4 - карбонаты.

Группа аутигенных минералов составляет больше половины тяжелой фракции лишь в глинистых прослоях, или в изолированных ими маломощных слоях песчано-алевритовых пород (табл. 2). Набор аутигенных минералов довольно типичен для древнепалеозойских терригенных пород региона и представлен титанистыми минералами (обычно анатазом), пиритом, гидроокислами железа, карбонатами и редкими зернами глауконита. Поверхность зерен последнего нередко покрыта фосфатной пленкой. В составе тяжелых аутигенных минералов наблюдаются значительные локальные вариации, обусловленные скорее всего доступностью разреза к выветриванию. Так, в разрезе скв. 1046 во многих пробах доминирует пирит и сравнительно мало гидроокислов железа. В пробах из обнажения, особенно в песчано-алевритовых разностях, много гидроокислов железа. Характерным аутигенным минералом в пробах стратотипического разреза является анатаз. В песчаноалевритовых породах он либо представлен таблитчатыми коричневыми, часто мутными кристаллами, в центральной части которых нередко сохраняется лейкоксен, либо образует мелкие кристаллы вокруг зерен лейкоксена. В глинистых прослоях анатаз часто представлен прозрачными тонкотаблитчатыми четырехугольными, светло-серыми с голубым или желтым оттенком, зональными кристаллами. 
По приведенным минералььным показателям юлгазеские отложения значительно отличаются от подстилающих пород тискреской свиты, характеризующихся кварцево-полевошпатовым составом и турмалиновоцирконовой ассоциацией (Менс, Пиррус, 1977). Граница этих двух стратонов, кроме увеличения зрелости кластогенного компонента и смены набора аллотигенных минералов, маркируется еще появлением апатита и: новышением содержания ильменита, а также своеобразием аутигенного минералогенеза (интенсивное анатазообразование, регенерация полевых шпатов и фосфатные пленки на кластогенных зернах).

Различия в минеральном составе кластогенного компонента между юлгазескими отложениями и покрывающими песчаниками маардуской пачки каллавереской свиты менее резкие. От маардуских песчаников, представленных мономинеральными кварцевыми разностями с цирконово-рутиловой ассоциацией (Хейнсалу, Вийдинг, 1978), юлгазеские отложения отличаются, кроме повышенного содержания турмалина, также соотношениями лейкоксена и ильменита и лейкоксенизацией последнего.

Из сказанного следует, что юлгазеские отложения стратотипической местности в минеральном отношении вполне индивидуализированы, что позволяет использовать минералогические критерии для выделения этих слоев в разрезе даже при отсутствии бностратиграфических показателей.

\section{Л И Т Е Р А Т У Р А}

Батурин В. П. Петрографический анализ геологического прошлого по терригенным компонентам. М.-Л., 1947.

Buйдинг X. A. Об интерпретации данных минералогического анализа. - В кн.: Методика и интерпретация результатов минералогических и геохимических исследований. Вильнюс, $1976,53-59$.

Лоог А., Кивимяги Э. Литостратиграфия пакерортского горизонта в Эстонии. - Изв. АН ЭССР. Хим. Геол., 1968, 17, 374-385.

Менс К. А., Пиррус Э. А. Стратотипические разрезы кембрия Эстонии. Таллин, 1977.

Mююрисепn $K$. $K$. Характеристика нижней границы пакерортского горизонта от мыса Пакерорт до реки Сясь. - Тр. Ин-та геол. АН ЭССР, 1958, 3, 55-79.

Mююрисепn $K$. K. Литостратиграфия пакерортского горизонта в Эстонской ССР по данным обнажений. - Тр. Ин-та геол. АН ЭССР, 1960, 5, 37-44.

Окнова Н.С. K вопросу о распределении минералов по гранулометрическим фракциям. - Докл. АН СССР, 1972, 203, 921-923.

Раукас $A$. Классификация обломочных пород и отложений по гранулометрическому составу. Таллин, 1981.

Рыьмусокс А., Лоог А., Кивимяги Э. О геологии и фауне юлгазеской пачки (нижний тремадок Северной Эстонии). - Уч. зап. Тартуского гос. ун-та. Тр. по геол., вып. 359, 7, 1975, 3-13.

Хейнсалу X., Вийдинд X. О минеральном составе нижнеордовикских фосфатоносных и подстилающих их отложений в Северной Эстонии. - Изв. АН ЭССР, Геол., $1978,27,46-52$.

$\begin{array}{cc}\text { Институт геологии } & \text { Поступила в редакцию } \\ \text { Академии наук Эстонской ССР } & 1 / \text { III } 1984\end{array}$

Kaisa MENS

\section{OLGASE KIHTIDE MINERALOOGIAST MAARDU OMBRUSES}

Artiklis on esitatud kahest läbilōikest (üks neist stratotüüpne) kogutud 21 proovi analüüsi tulemustele tuginev ülgase kihistu mineraloogiline iseloomustus.

Olgase kivimite granulomeetriast lähtudes on mineraalide keskmised sisaldused arvutatud eraldi liivakivide-aleuroliitide ja savikivimite kohta. 
Analüüsi tulemused näitavad, et ülgase kihid on mineraloogiliselt täiesti omanäolised, nad erinevad mineraalikoosluste poolest nii lamavatest tiskre kihistu kui ka lasuvatest maardu kihistiku kallavere kihistu omadest. See võimaldab paleontoloogilise materjali puudumisel või selle halval säilimisel kasutada mineraloogilisi kriteeriume ülgase kihistu eraldamiseks läbilōikes.

\section{Kaisa MENS}

\section{ON THE MINERALOGY OF THE OLGASE BEDS IN MAARDU DISTRICT}

The present mineralogical determination is based on the study of the mineral composition in the coarse silt fraction $(0.1-0.05 \mathrm{~mm})$ of 21 samples collected from two sections, one of them being the stratotype of the Ulgase Formation (Fig. 1).

The results of the study are given in Table 2, and their total average for sandsiltstones (I) and claystones (II) separately in Fig. 3. The content of light minerals (A), heavy minerals (B), and the numerical relations in the group of the nonopaque allothigenous heavy minerals (B) and those in the group of authigenous heavy minerals (Г) are shown.

The most typical features of the mineral composition are represented in allothigenous groups as follows: high mineralogical maturity (see quartz-feldspar ratio in Table 2); zircon-tourmaline-rutile assemblage; continual presence of apatite and unstable minerals (commonly amphiboles); simultaneous occurrence of ilmenite and leucoxene with the former prevailing (see the last column in Table 2). Authigenic mineralization is characterized by an/ extensive replacement of leucoxene by anatase, limpid overgrowths on detrital feldspar grains and phosphatic pellicles on some detrital minerals (quartz, zircone, ilmenite).

The Ulgase Beds of the studied area differ clearly by their mineral composition from the underlying (the Tiskre Formation, Lower Cambrian) as well as from the overlying (the Maardul Member of the Kallavere Formation, Ordovician) deposits. The difference lies in the content of some minerals, particularly in mineral associations, mostly of the heavy fraction.

Thus, the described unit can be recognized on the basis of the peculiarities of its mineral composition, especially in the sequences where faunal criteria are lacking. 